\title{
The influence of exendin and GLP-1 on VCAM-1 and ICAM-1 production in endothelium stimulated by TNF- $\alpha$ and glycated albumin
}

\author{
Krzysztof Siemianowicz*, Tomasz Francuz, Wojciech Garczorz \\ Department of Biochemistry, Medical University of Silesia, Katowice, Poland; \\ ${ }^{*}$ Corresponding Author: ksiem@mp.pl
}

Received 6 November 2012; revised 13 December 2012; accepted 24 December 2012

\section{ABSTRACT}

A growing body of evidence indicates that incretins may have pleiotropic beneficial effects beyond lowering glucose blood concentration. The effect of GLP-1 and exendin-4 on coronary arteries endothelium in diabetic and obese individuals has been studied widely. TNF- $\alpha$ is one of adipocytokines. The aim of our study was to evaluate the influence of glycated albumin (GlyAlb; $100 ; 500$ and $1000 \mathrm{mg} / \mathrm{L}$ ) and pro-inflammatory cytokine, TNF- $\alpha$ (2.5 and $10 \mathrm{ng} / \mathrm{mL})$, on expression of ICAM-1 and VCAM-1 in cultured human endothelial cells derived from coronary arteries. The next goal of the study was to evaluate the influence of GLP-1 (10 nM and $100 \mathrm{nM})$ and its analogue, exendin-4 (1 nM and $10 \mathrm{nM})$, on the expression of ICAM-1 and VCAM-1 in these cell line. TNF- $\alpha$ statistically significantly increased VCAM-1 production by endothelial cells, whereas GlyAlb statistically significantly augmented the expression of both tested adhesion molecules. Exendin-4 and GLP-1 statistically significantly reduced the expression of VCAM-1 in endothelial cells stimulated by GlyAlb in dose-dependent manner. When TNF- $\alpha$ was used as the stimulant only exendin- 4 in the concentration of $10 \mathrm{nM}$ statistically significantly reduced the expression of VCAM-1. Studied incretins in their both concentrations statistically significantly reduced the expression of ICAM-1 in endothelial cells stimulated by GlyAlb. The influence of TNF$\alpha$ on the expression of ICAM-1 was statistically significantly reduced by both concentrations of exendin- 4 but only by the higher concentration of GLP-1. The results of our present study indicate that incretins may present a group of agents developing pleiotropic effects beyond the reduction of blood glucose concentration. Their vaso- protective and cardioprotective action may be of importance in diabetic and obese individuals.

Keywords: Incretins; Endothelium; Adhesion Molecules

\section{INTRODUCTION}

Over the past two decades the rate of obesity has risen and around $50 \%$ of all adults in Europe are now classified as overweight. Obesity is a major risk factor for the development of diabetes and predisposes individuals to dyslipideamia and hypertension. Insulin resistance accompanied by visceral (central) obesity may lead not only to arterial hypertension, but some metabolic disorders such as hyperglycaemia, low high-density lipoprotein cholesterol level and hypertriglyceridaemia. According to National Cholesterol Education Program (NCEP) classification, the presence of three out of five of above factors allows to diagnose metabolic syndrome (MS). This constellation of cardiovascular risk factors tremendously increases risk for cardiovascular diseases. In particular, visceral obesity is strongly correlated with insulin resistance and dyslipidaemia $[1,2]$.

Adipocytes secret various cytokines including leptin, adiponectin, plasminogen activator inhibitor-1 (PAI-1) and TNF- $\alpha$. They are termed adipocytokines. Some of them inhibit insulin signaling pathways. Tumor necrosis factor alfa $(\mathrm{TNF}-\alpha)$ is a proinflammatory cytokine originally defined by its antitumor activity. TNF- $\alpha$ is one of adipocytokines. Under normal circumstances it circulates in low concentration. The adipose tissue of obese humans contains increased numbers of macrophages, and once activated these macrophages are responsible for the production of most of the tissue's TNF- $\alpha$. Chronic inflammation associated with central obesity results in insulin resistance and dyslipidaemia and predicts the development of type 2 diabetes mellitus. The endothelial dysfunction occurring in the metabolic syndrome is the result of the 
effect of inflammatory cytokine, TNF- $\alpha$ [3-5].

Intracellular adhesion molecule-1 (ICAM-1) and vascular adhesion molecule-1 (VCAM-1) are considered as endothelial dysfunction markers. These molecules mediate the adhesion of leukocytes to the surface of endothelium and participate in their migration to subendothelial layer of a blood vessel. Activation of endothelial cells results in the altered production of ICAM-1 and VCAM-1.

Elevated blood glucose level observed in diabetic patients leads to spontaneous chemical reaction between carbohydrates and both plasma and tissue proteins. Hyperglycemia induces an overproduction of reactive oxygen species as well. Long-lived tissue proteins undergo sequential glycation and oxidation forming glycooxidative products which are termed advanced glycation end-products (AGEs) [6]. Incretin therapy has been approved for the treatment of type 2 diabetes mellitus. Glucagon-like peptide-1 (GLP-1) is one of incretin hormones and is secreted from $\mathrm{L}$ cells in the intestine in response to food intake. GLP-1 has an important physiological function in augmenting postprandial insulin secretion. Exendin-4 is a potent and long-acting GLP-1 analogue. A growing body of evidence suggests that GLP-1 may have additional beneficial effects like induction of satiety and associated body weight reduction $[7,8]$. Because of this pleiotropic effects GLP-1 and its analogues should be of special interest in obese diabetic patients or individuals with MS. GLP-1 receptors are expressed in components of cardiovascular system such as cardiomyocytes, endocardium, microvascular endothelium and coronary smooth muscle cells [9]. The direct effects of GLP-1 on vascular injury in diabetes are largely unknown. Ishibashi et al. [10] pointed out that GLP-1 inhibited RAGE expression and AGEinduced up-regulation of VCAM-1 and ICAM-1 gene expression in human umbilical vein endothelial cells (HUV EC).

Metabolic syndrome represents a combination of synergistic vascular pathologies that leads to an accelerated atherogenic state that comprises the ability of the patient to satisfactorily respond to various humoral, cellular and mechanical stress. In patients with MS coronary arteries are very susceptible to the development of atherosclerosis. These patients are at an elevated risk of coronary heart disease and myocardial infarction.

The aim of our study was to evaluate the influence of glycated albumin (GlyAlb; 100; 500 and $1000 \mathrm{mg} / \mathrm{L}$ ) and pro-inflammatory cytokine, TNF- $\alpha(2.5$ and $10 \mathrm{ng} / \mathrm{mL})$, on expression of ICAM-1 and VCAM-1 in cultured human endothelial cells derived from coronary arteries. The next goal of the study was to evaluate the influence of GLP-1 (10 nM and $100 \mathrm{nM}$ ) and its analogue, exendin-4 ( $1 \mathrm{nM}$ and $10 \mathrm{nM}$ ), on the expression of ICAM-1 and VCAM-1 in his cell line.

\section{MATERIALS AND METHODS}

\subsection{Endothelial Cell Culture}

For all subsequent experiments human coronary artery endothelial cells (CAEC) purchased in Lonza were used. Cells were cultured according to cell supplier's recommendations in EGM-2 with SingleQuots (Lonza) supplement and $5 \%$ fetal bovine serum at $37^{\circ} \mathrm{C}$ in $5 \% \mathrm{CO}_{2}$ humidified incubator. Endothelial cells were identified using monoclonal antibody against von Willebrand factor and by their typical morphology. Cell viability and morphology were assessed for each experimental group. Before experiments, cells were plated on 12-well cell culture plates and maintained till confluence. After reaching $80 \%$ confluence, cells were treated with tested substances for $24 \mathrm{~h}$. After that time cell medium was transferred into sterile test-tubes and centrifuged $\left(15 \mathrm{~min}, 15,000 \mathrm{~g}, 4^{\circ} \mathrm{C}\right)$ to remove cells. Obtained cell medium was divided into test tubes and frozen at $-80^{\circ} \mathrm{C}$ until the time of testing.

\subsection{ICAM-1 and VCAM-1 Protein Assay}

Determination of ICAM-1 and VCAM-1 concentration in cell culture medium was done by DuoSet ${ }^{\mathrm{TM}}$ ELISA kits (R\&D Systems), using 96-well plates in compliance with manufacturer's instructions. Absorbance was measured at 450 and $545 \mathrm{~nm}$ with a Stat Fax 2100 Microplate Reader. Calibration curves were prepared with the recombinant proteins used as a reference standard. Concentrations of VCAM-1 and ICAM-1 were normalized, using the concentration of the total cellular protein, which is proportional to the cell number.

\subsection{Total Protein Assay}

After incubation, the cells were washed twice with PBS buffer. They were then lysed with $0.5 \mathrm{ml}$ of cooled RIPA buffer (pH 7.6, $25 \mathrm{mM}$ Tris $\mathrm{HCl}, 150 \mathrm{mM} \mathrm{NaCl}$, $1 \%$ NP-40, $1 \%$ sodium deoxycholate, $0.1 \%$ SDS). The total protein concentration was determined in duplicate with the bicinchoninic acid method, using 96-well plates. Absorbance was measured at $560 \mathrm{~nm}$ with a Stat Fax 2100 Microplate Reader.

\subsection{Experiment Design}

For cells stimulation human recombinant TNF- $\alpha$ and human glycated albumin were used. To assess the influence of TNF- $\alpha$ and glycated albumin on ICAM- 1 and VCAM-1 expression, cells were incubated with TNF- $\alpha$ at concentration of 2.5 and $10 \mathrm{ng} / \mathrm{mL}$ and glycated albumin at concentration of 100,500 and $1000 \mathrm{mg} / \mathrm{L}$. To test the dose-effect relation of tested incretins, cells were incubated with exendin- 4 in concentrations 1 or $10 \mathrm{nM}$ or GLP-1 in concentrations 10 or $100 \mathrm{nM}$. Because of high 
expression of functional dipetydyl peptidase IV (DPP-4) on CAEC surface, cells treated with GLP-1 were co-incubated with DPP-4 inhibitor KR-62436 in concentration $5.7 \mu \mathrm{M}$. The influence of KR-62436 alone on ICAM-1 and VCAM-1 expression was tested in another experiment and found not to be significant (data not shown).

\subsection{Statistical Analysis}

All values were presented as mean \pm SD expressed as percent in compare to control group. One-way ANOVA followed by the Scheffe F test was performed for statistical comparisons; $\mathrm{p}<0.05$ was considered significant. All statistical analyses were performed using Statistica 9.0 analysis toolpack.

All reagents were purchased in Sigma unless stated otherwise.

\section{RESULTS}

TNF- $\alpha$ in both tested concentrations statistically significantly increased VCAM-1 production by endothelial cells. Glycated albumin in all three tested concentrations statistically significantly augmented the expression of both tested adhesion molecules. The elevation of VCAM-1 and ICAM- 1 caused by TNF- $\alpha$ in both concentrations was statistically significantly greater than resulting from the addition of GlyAlb in all tested concentration (Figures 1 and 2). The dose dependent manner of this elevation was only detected for ICAM-1 and the stimulation by GlyAlb (Figure 2).

The addition of both studied incretins to unstimulated cell culture in all tested concentrations did not influence the expression of studied adhesion molecules. Both, exendin-4 and GLP-1 statistically significantly reduced the expression of VCAM-1 in endothelial cells stimulated by GlyAlb in dose-dependent manner (Figure 3). When TNF- $\alpha$ was used as the stimulant only exendin- 4 in the concentration of $10 \mathrm{nM}$ statistically significantly reduced the expression of VCAM-1 (Figure 4).

Studied incretins in their both concentrations statistically significantly reduced the expression of ICAM-1 in endothelial cells stimulated by GlyAlb (Figure 5). The influence of TNF- $\alpha$ on the expression of ICAM-1 was statistically significantly reduced by both concentrations of exendin- 4 but only by the higher concentration of GLP-1 (Figure 6).

\section{DISCUSSION}

The major causes of morbidity and mortality in subjects with diabetes are related to the development of cardiovascular disease, especially coronary heart disease (CHD). A 10-year post-randomization follow up of a study of the tight glucose intervention of the United Kingdom Prospective Diabetes Study (UKPDS) as well as Action to Control Cardiovascular Risk in Diabetes (ACCORD), and metanalysis of four randomized, controlled trials have shown that intensive glucose control is associated with a reduced risk of myocardial infarction (MI) [11].

Hypoglycemic drugs affecting incretin system seem to develop beneficial effects on vascular system. An experimental study revealed that infusion of GLP-1 improved the viability of mouse cardiomyocytes and the functional recovery, and reduced the infarct size [12]. Endothelium,

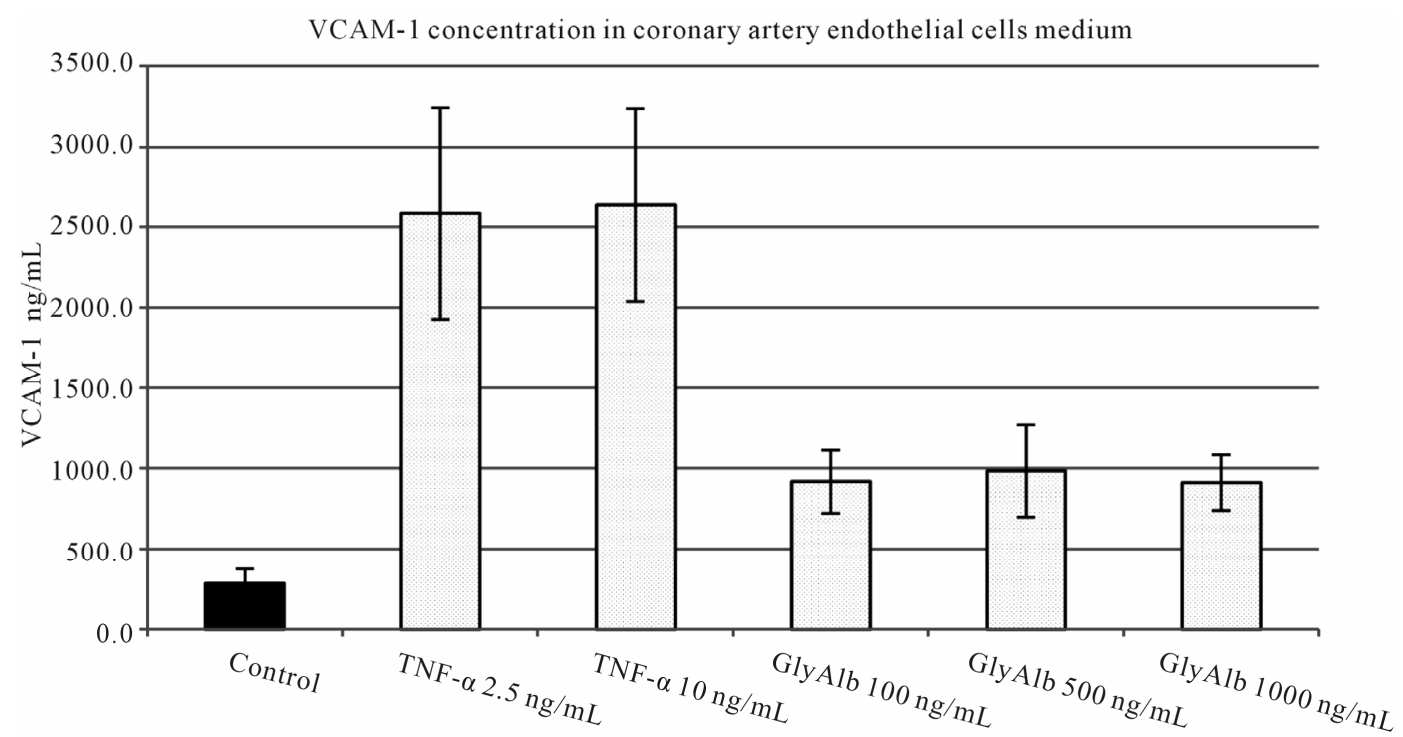

Figure 1. VCAM-1 concentration in medium of coronary artery endothelial cells stimulated with TNF- $\alpha$ $(2.5$ and $10 \mathrm{ng} / \mathrm{mL}$ ) or glycated albumin (GlyAlb, $100 \mathrm{mg} / \mathrm{L} ; 500 \mathrm{mg} / \mathrm{L} ; 1000 \mathrm{mg} / \mathrm{L})$. All values are expressed as mean \pm SD of 8 repeats. Both, TNF- $\alpha$ and glycated albumin stimulated secretion of VCAM-1 (p vs control $<0.001)$. 


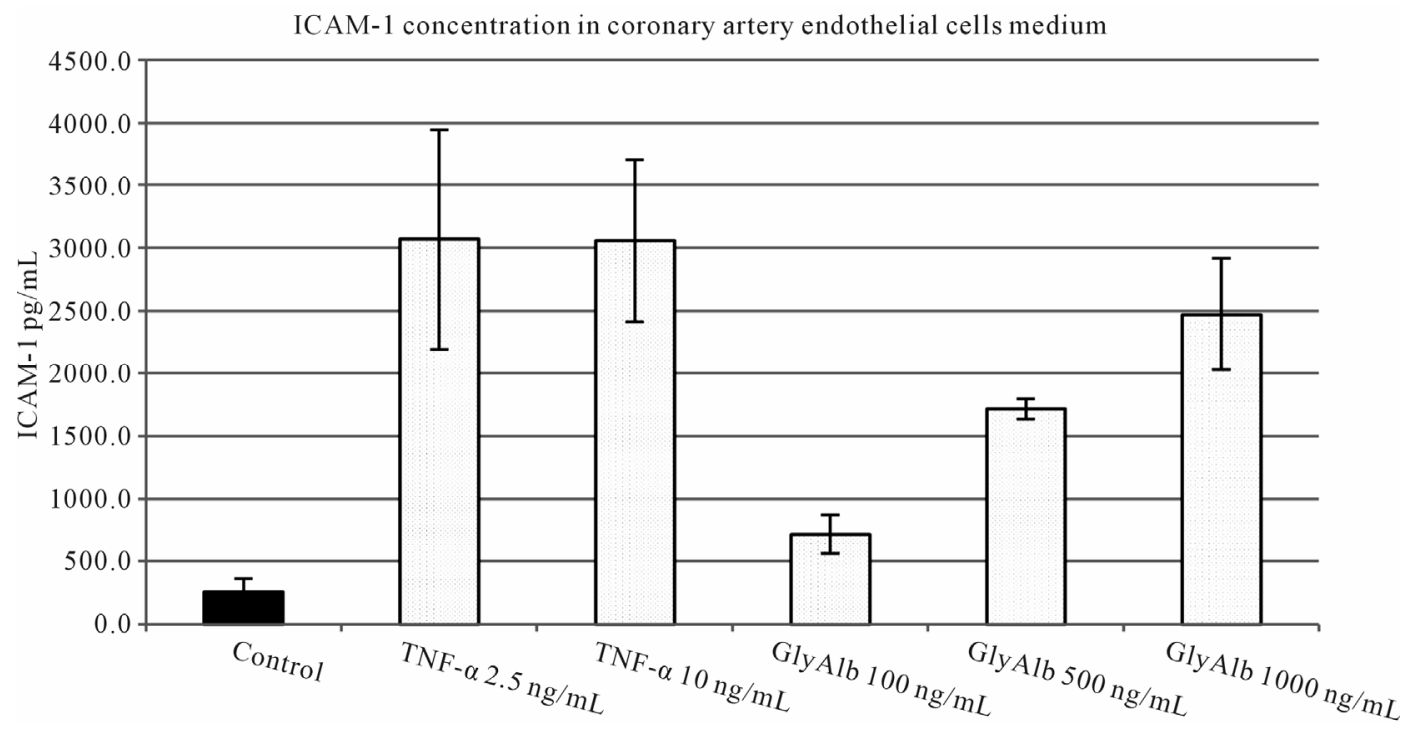

Figure 2. ICAM-1 concentration in medium of coronary artery endothelial cells stimulated with TNF- $\alpha$ (2.5 and $10 \mathrm{ng} / \mathrm{mL}$ ) or glycated albumin (GlyAlb, $100 \mathrm{mg} / \mathrm{L} ; 500 \mathrm{mg} / \mathrm{L} ; 1000 \mathrm{mg} / \mathrm{L}$ ). All values are expressed as mean \pm SD of 8 repeats. TNF- $\alpha$ stimulated secretion of ICAM-1 ( $p$ vs control $<0.005)$, glycated albumin stimulated ICAM-1 secretion in dose dependent manner ( $\mathrm{p}$ vs control $<0.001)$.

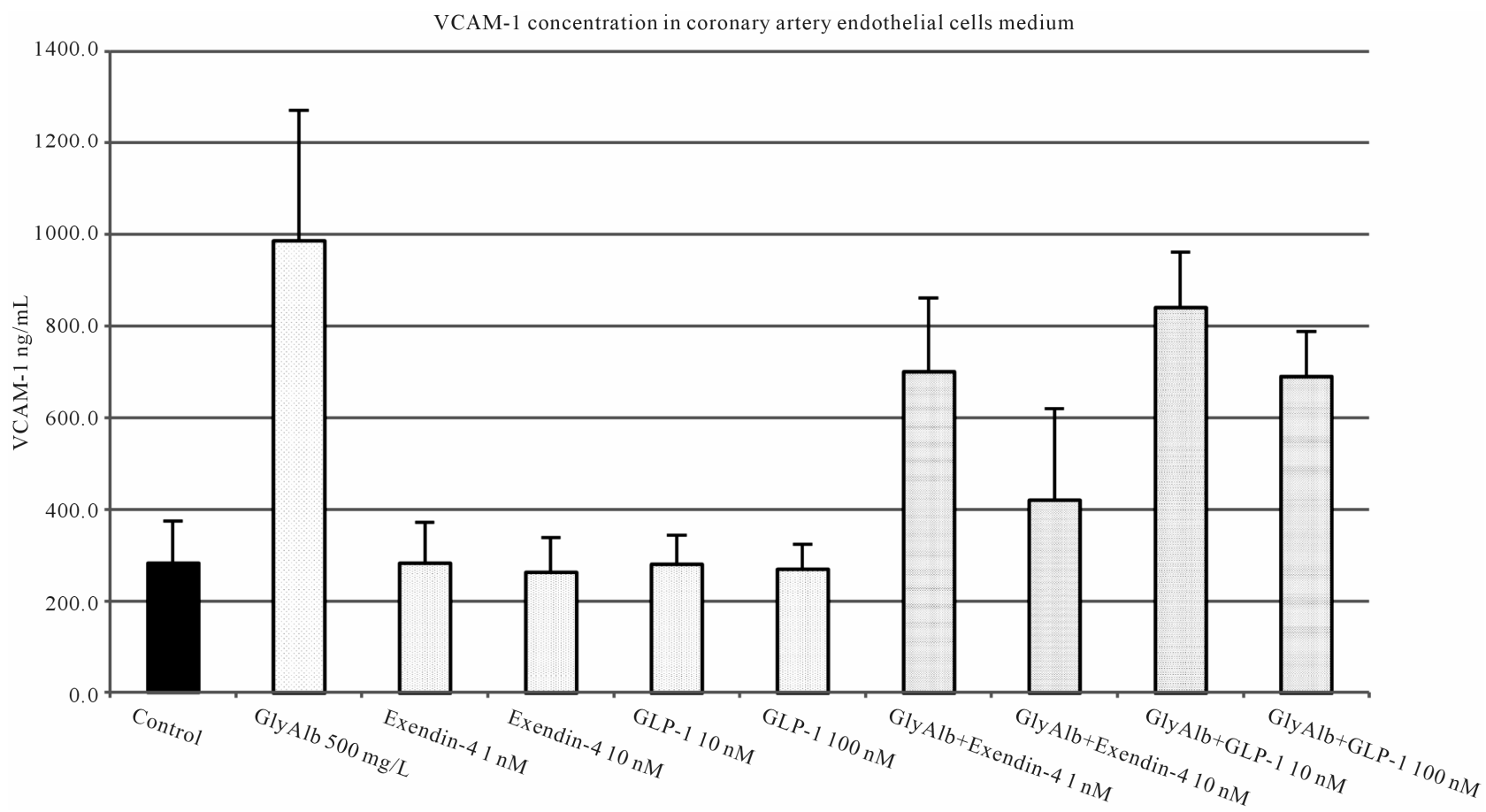

Figure 3. VCAM-1 concentration in medium of coronary artery endothelial cells stimulated with glycated albumin (GlyAlb, 500 $\mathrm{mg} / \mathrm{L})$, GLP-1 (10 or $100 \mathrm{nM})$ and exendin $4(1$ or $10 \mathrm{nM})$. All values are expressed as mean \pm SD of 8 repeats. Both, GLP-1 and exendin 4 decreased glycated albumin stimulated expression of VCAM-1 $(\mathrm{p}<0.01)$. The inhibitory effect of exendin $4(10 \mathrm{nM})$ was significantly higher than GLP-1 $(100 \mathrm{nM}), \mathrm{p}<0.05$. However, observed VCAM-1 concentration in cells incubated with glycated albumin and tested incretins was still significantly higher than in control $(\mathrm{p}<0.01)$.

cardiac and vascular myocytes express GLP-1 receptor. However, the cardioprotective actions of GLP-1 are both receptor dependent and independent [9]. Arakawa et al. [13] observed that in vitro mouse macrophages treated with Exendine-4 suppressed the TNF- $\alpha$ mRNA expression. This observation gives an assumption that the exendine- 4 therapy may lead to an inhibition of inflammatory response of macrophages. 


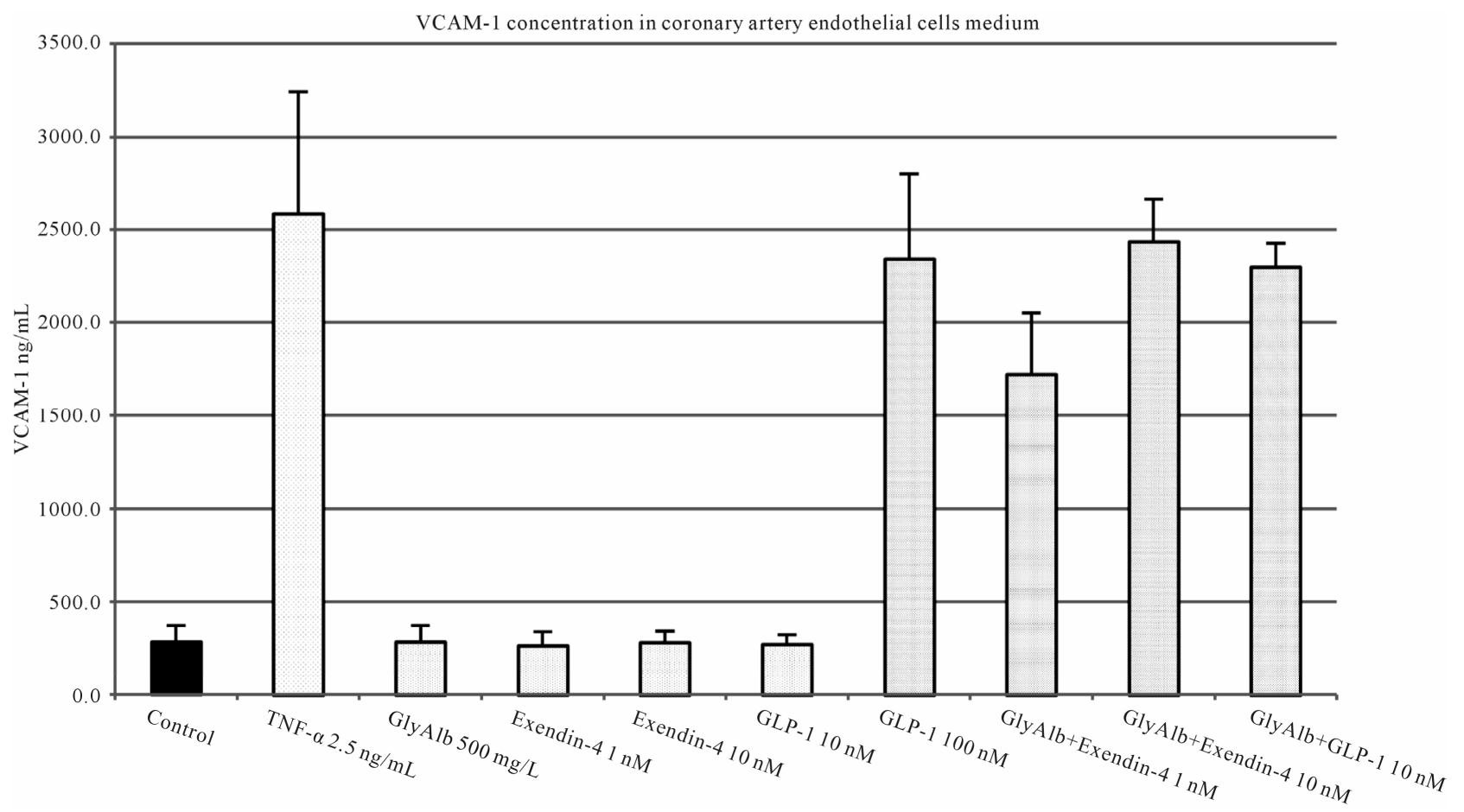

Figure 4. VCAM-1 concentration in medium of coronary artery endothelial cells stimulated with TNF- $\alpha$ (2.5 ng/L), GLP-1 (10 or $100 \mathrm{nM})$ and exendin $4(1$ or $10 \mathrm{nM})$. All values are expressed as mean \pm SD of 8 repeats. Both, GLP-1 and exendin 4 decreased TNF- $\alpha$ stimulated expression of VCAM-1 $(\mathrm{p}<0.01)$. The inhibitory effect of exendin $4(10 \mathrm{nM})$ was significantly higher than GLP-1 $(100 \mathrm{nM}), \mathrm{p}<0.01$. However, observed VCAM-1 concentration in cells incubated with glycated albumin and tested incretins was still significantly higher than in control $(\mathrm{p}<0.001)$.

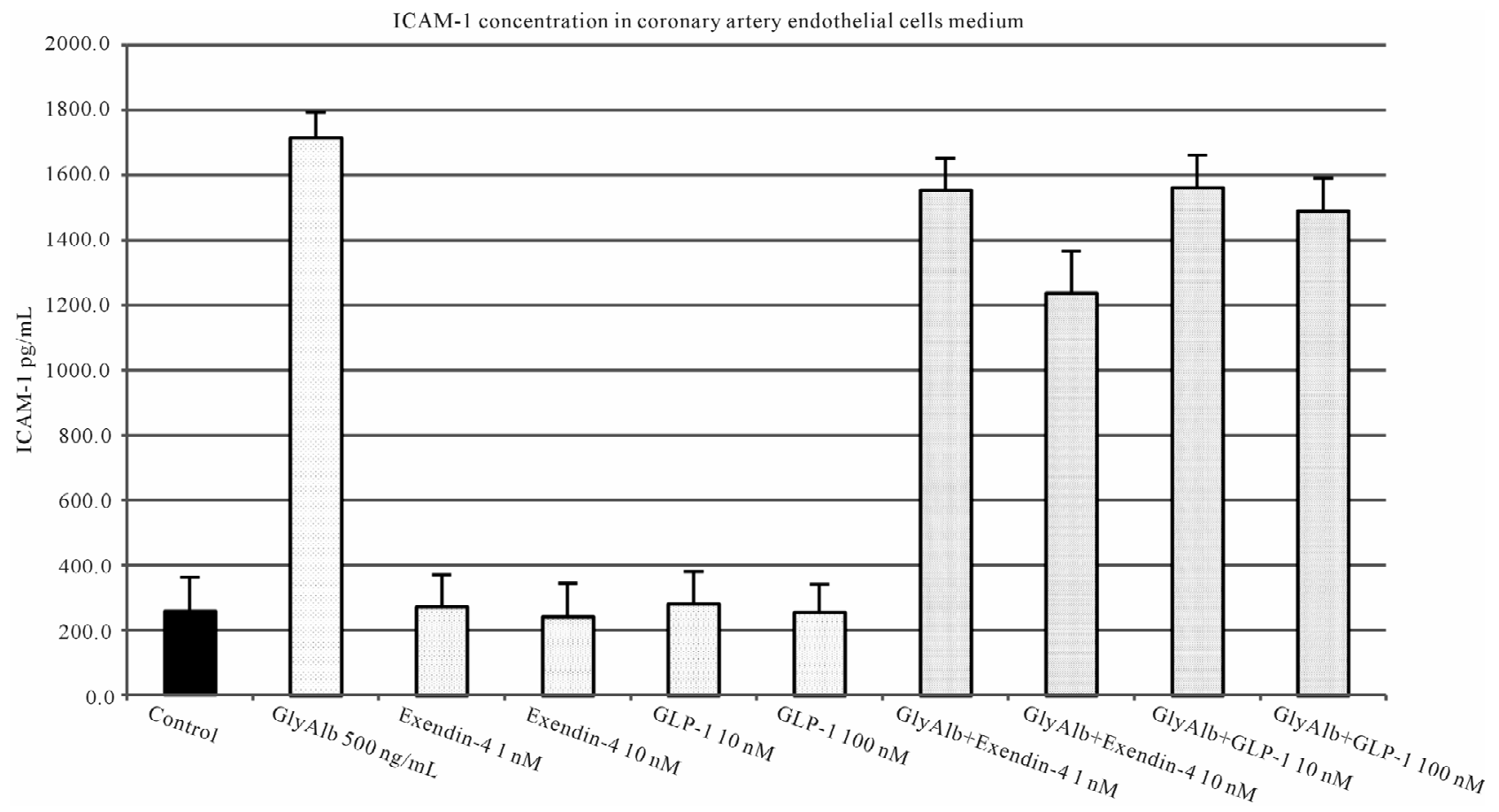

Figure 5. ICAM-1 concentration in medium of coronary artery endothelial cells stimulated with glycated albumin (GlyAlb, 500 $\mathrm{mg} / \mathrm{L})$, GLP-1 (10 or $100 \mathrm{nM})$ and exendin 4 (1 or $10 \mathrm{nM})$. All values are expressed as mean \pm SD of 8 repeats. Both, GLP-1 and exendin 4 decreased glycated albumin stimulated expression of ICAM-1 $(\mathrm{p}<0.01)$. The inhibitory effect of exendin $4(10 \mathrm{nM})$ was significantly higher than GLP-1 $(100 \mathrm{nM}), \mathrm{p}<0.5$. However, observed ICAM-1 concentration in cells incubated with glycated albumin and tested incretins was still significantly higher than in control $(\mathrm{p}<0.01)$. 


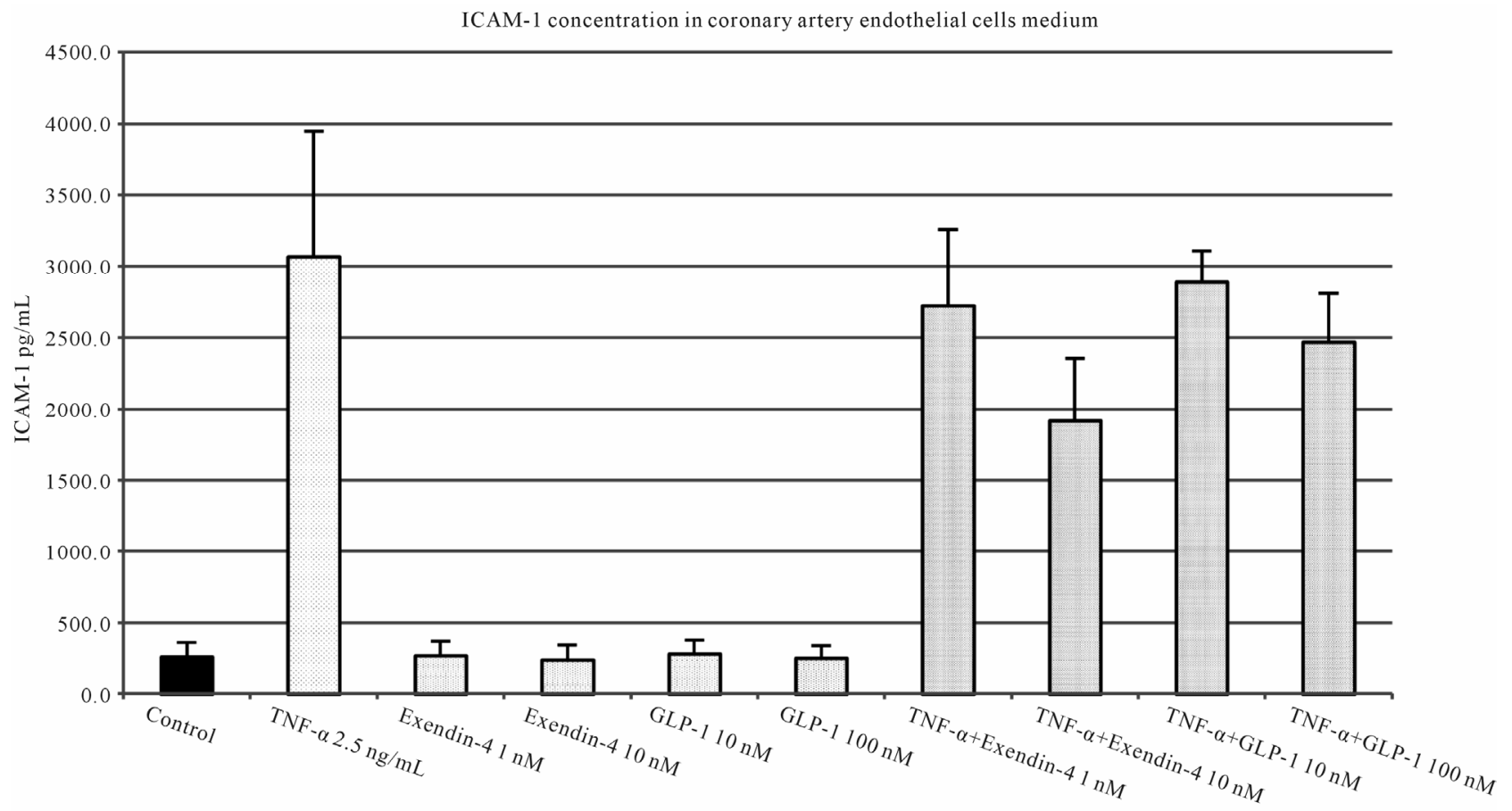

Figure 6. ICAM-1 concentration in medium of coronary artery endothelial cells stimulated with TNF- $\alpha$ (2.5 ng/L), GLP-1 (10 or 100 $\mathrm{nM})$ and exendin $4(1$ or $10 \mathrm{nM})$. All values are expressed as mean \pm SD of 8 repeats. Both, GLP-1 and exendin 4 decreased TNF- $\alpha$ stimulated expression of ICAM-1 $(p<0.01)$. The inhibitory effect of exendin $4(10 \mathrm{nM})$ was significantly higher than GLP-1 $(100$ $\mathrm{nM}), \mathrm{p}<0.05$. However, observed ICAM-1 concentration in cells incubated with glycated albumin and tested incretins was still significantly higher than in control $(\mathrm{p}<0.001)$.

Swedish researchers evaluated the vasoprotective effects of exenatide, synthetic analog of exendin-4. They chose a different experimental model. Preincubation with Intralipid $^{\circledR}$ induced endothelial dysfunction, but exenatide did not protect against it [14]. In another study GLP-1 was observed to cause a dose-dependent relaxation of rat aorta acting by its receptor [15]. As results from animal model have suggested the vasoprotective role of incretins, researchers have focused their interest on human endothelium. The result of in vitro or animal studies cannot be simply extrapolated on humans. Kelly et al. [16] evaluated the effects of GLP-1 agonist, exenatide and metformin of endothelial function. Both medications were administered to prediabetic patients with visceral obesity for 3 months. Both treatments did not significantly influenced VCAM-1 and C-reactive protein. The most popular model of cell culture of human endothelium is HUVEC. GLP-1 was shown to reduce an expression of plasminogen activator inhibitor-1 (PAI-1) in HUVEC stimulated by TNF- $\alpha$ [17]. Ishibashi et al. observed that GLP-1 inhibited in HUVEC the expression of VCAM-1 mRNA up regulated by AGE [10]. Several researchers evaluated the influence of GLP-1 or GLP-1 receptor agonists on endothelium. In a study performed on healthy, nondiabetic, normotensive nonsmokers with no family history of diabetes GLP-1 infusion enhanced an acethylcholine mediated vasoconstriction [18]. GLP-1 agonist, liraglutide, reduced the expression of a vascular adhesion molecule and intracellular adhesion molecule-1 elicited by TNF- $\alpha$. The stimulation of GLP-1 receptor resulted also in an increased expression of endothelial nitric oxide synthase [19]. GLP-1 inhibited advanced glycation end products induced up regulation of VCAM-1 mRNA in HU VEC [10]. In our experiment two agents were chosen to stimulate endothelium from coronary artery. TNF- $\alpha$ represented a risk factor present in obese patients whereas GlyAlb represented a risk factor observed in diabetic subjects. As we have used a different experimental model, our results indicate, that incretins may have a cardioprotective effect not only in diabetic patients, but in obese individuals as well.

Our experiment confirmed that beneficial influence of incretins on HUVEC stimulated by TNF- $\alpha$ and AGE can be also detected in endothelium derived from coronary arteries. Dozier et al. revealed that GLP-1 attenuated the increase of microvascular permeability induced by lipopolysaccharide (LPS) in mesenteric endothelium. This observation points another mechanism in which GLP-1 may protect endothelium and vascular wall during inflammation [20]. Exendin-4 was also shown to protect glomerular endothelium in diabetic rats by reducing the production of ICAM- 1 and type IV collagen. Exendin-4 also 
attenuated release of proinflammatory cytokines from macrophages. The authors of this study concluded that exendin-4 might prevent disease progression in the early stage of diabetic nephropathy [21]. As endothelium dysfunction in patients with diabetic retinopathy was the point of interest of one of our previous studies [22], in our next study (unpublished results) we observed a protective effect GLP-1 and exendin-4 on human retinal pigment epithelial cells.

The results of our present study and other results discussed here indicate that incretins may present a group of agents developing pleiotropic effects beyond the reducetion of blood glucose concentration. Their vasoprotective effects have been reported in organs crucial for the development of diabetic complications. Incretins by improving the endothelial dysfunctions may protect against vascular complications of diabetes or delay their onset.

\section{REFERENCES}

[1] James, P.T., Rigby, N., Leach, R. and International Obesity Task Force (2004) The obesity epidemic, metabolic syndrome and future prevention strategies. European Journal of Cardiovascular Prevention and Rehabilitation, 11, 3-8. doi:10.1097/01.hjr.0000114707.27531.48

[2] Kocełak, P., Chudek, J. and Olszanecka-Glinianowicz, M. (2012) Prevalence of metabolic syndrome and insulin resistance in overweight and obese women according to the different diagnostic criteria. Minerva Endocrinologica, 37, 247-254.

[3] Pichi, A., Gao, X., Belmadani, S., Potter, B.J., Focardi M., Chilian, W.M. and Zhang, C. (2006) Tumor necrosis factor- $\alpha$ induces endothelial dysfunction in the prediabetic metabolic syndrome. Circulation Research, 99, 69-77. doi:10.1161/01.RES.0000229685.37402.80

[4] Vykoukal, D. and Davies, M.G. (2011) Vascular biology of metabolic syndrome. Journal of Vascular Biology, 54, 819-831. doi:10.1016/j.jvs.2011.01.003

[5] Yudkin, J.S. (2007) Inflammation, obesity, and the metabolic syndrome. Hormone and Metabolic Research, 39, 707-709. doi:10.1055/s-2007-985898

[6] Thorpe, S.R. and Baynes, J.W. (1996) Role of Maillard reaction in diabetes mellitus and diseases of aging. Drugs Aging, 9, 69-77. doi:10.2165/00002512-199609020-00001

[7] Brubaker, P.L. (2007) Incretin-based therapies: Mimetics versus protease inhibitors. Trends in Endocrinology and Metabolism, 18, 240-245. doi:10.1016/i.tem.2007.06.005

[8] Lovshin, J.A. and Drucker, D.J. (2009) Incretin-based therapies for type 2 diabetes mellitus. Nature Reviews Endocrinology, 5, 262-269. doi:10.1038/nrendo.2009.48

[9] Ban, K., Noyan-Ashraf, M.H., Hoefer, J., Bolz, S.S., Drucker, D.J. and Husain, M. (2008) Cardioprotective and vasodilatory actions of glucagon-like peptide 1 receptor are mediated through both glucagon-like peptide 1 receptor-dependent and -independent pathways. Circulation,
117, 2340-2350. doi:10.1161/CIRCULATIONAHA.107.739938

[10] Ishibashi, Y., Matsui, T., Takeuchi, M. and Yamagishi, S. (2010) Glucagon-like peptide-1 (GLP-1) inhibits advanced glycation end product (AGE)-induced up-regulation of VCAM-1 mRNA levels in endothelial cells by suppressing AGE receptor (RAGE) expression. Biochemical and Biophysical Research Communications, 391, 1405 1408. doi:10.1016/j.bbrc.2009.12.075

[11] MacIsaac, R.J. and Jerums G. (2011) Intensive glucose control and cardiovascular outcomes in type 2 diabetes (April 2010). Heart, Lung and Circulation, 20, 647-654. doi:10.1016/j.hlc.2010.07.013

[12] Ban, K., Kim, K.-H., Cho, C.-K., Sauvé, M., Diamandis, E.P., Backx, P.H., Drucker, D.J. and Husain, M. (2010) Glucagon-like peptide (GLP)-1 (9-36) amide-mediated cytoprotection is blocked by exendin (9-39) yet does not require the known GLP-1 receptor. Endocrinology, 151, 1520-1531. doi:10.1210/en.2009-1197

[13] Arakawa, M., Mita, T., Azuma, K., Ebato, C., Goto, H., Nomiyama, T., Fujitani, Y., Hirose, T., Kawamori, R. and Watada, H. (2010) Inhibition of monocyte adhesion to endothelial cells and attenuation of atheroclerotic lesion by a glucagon-like peptide-1 receptor agonist, exendine-4. Diabetes, 59, 1030-1037. doi:10.2337/db09-1694

[14] Nathanson, D., Erdogdu, Ö., Pernow, J., Zhang, Q. and Nyström, T. (2009) Endothelial dysfunction induced by triglycerides is not restored by exenatide in rat conduit arteries ex vivo. Regulatory Peptides, 157, 8-13. doi:10.1016/j.regpep.2009.07.003

[15] Green, B.D., Hand, K.V., Dougan, J.E., McDonnell, B.M., Cassidy, R.S. and Grieve, D.J. (2008) GLP-1 and related peptides cause concentration-dependent relaxation of rat aorta through a pathway involving $\mathrm{K}_{\mathrm{ATP}}$ and cAMP. Archives of Biochemistry and Biophysics, 478, 136-142. doi:10.1016/j.abb.2008.08.001

[16] Kelly, A.S., Bergenstal, R.M., Gonzales-Campy, J.M., Katz, H. and Bank, A.J. (2012) Effects of exenatide vs metformin on endothelial function in obese patients with pre-diabetes: A randomized trial. Cardiovascular Diabetology, 11, 64.

http://www.cardiodiab.com/content/11/1/64

[17] Liu, H., Hu, Y., Simpson, R.W. and Dear, A.E. (2008) Glucagon-like peptide-1 attenuates tumor necrosis factor$\alpha$-mediated induction of plasmogen activator inhibitor-1 expression. Journal of Endocrinology, 196, 57-65. doi:10.1677/JOE-07-0387

[18] Basu, A., Charkoudian, N., Schrage, W., Rizza, R.A., Basu, R. and Joyner M.J. (2007) Beneficial effects of GLP-1 on endothelial function in humans: Dampening by glyburide but not by glimeperide. American Journal of Physiology-Endocrinology and Metabolism, 293, E1289E1295. doi:10.1152/ajpendo.00373.2007

[19] Gaspari, T., Liu, H.B., Welungoda, I., Hu, Y., Widdop, R.E., Knudsen, L., Simpson, R.W. and Dear, A.E. (2011) A GLP-1 receptor agonist liraglutide inhibits endothelial cell dysfunction and vascular adhesion molecule expression in an $\mathrm{ApoE}^{-/-}$mouse model. Diabetes \& Vascular Disease Research, 8, 117-124. 
$\underline{\text { doi: } 10.1177 / 1479164111404257}$

[20] Dozier, K.C., Cureton, E.L., Kwan, R.O., Curran, B., Sadjadi, J. and Victorino, G.P. (2009) Glucagon-like peptide-1 protects mesenteric endothelium from injury during inflammation. Peptides, 30, 1735-1741. doi:10.1016/j.peptides.2009.06.019

[21] Kodera, R., Shikata, K., Kataoka, H.U., Takatsuka, T, Miyamoto, S., Sasaki, M., Kajitani, N., Nishishita, S., Sarai, K., Hirota, D., Sato, C., Ogawa, D. and Makino H.
(2011) Glucagon-like peptide-1 receptor agonist ameliorates renal injury through its anti-inflammatory action without lowering blood glucose level in a rat model of type 1 diabetes. Diabetologia, 54, 965-978. doi:10.1007/s00125-010-2028-X

[22] Siemianowicz, K., Francuz, T., Gminski, J., Telega, A. and Syzdól, M. (2005) Endothelium dysfunction markers in patients with diabetic retinopathy. International Journal of Molecular Medicine, 15, 459-462. 